\title{
SAÚDE MENTAL NO TRABALHO: UM CONVITE AO DIALÓGICO
}

\author{
Mental Health at Work: an Invitation to Dialogue \\ Salud Mental en el Trabajo: una Invitación al Diálogo
}

Euina Eunice M. Pietrani

\begin{abstract}
Resumo: O ensaio busca refletir sobre os aspectos que norteiam o mundo do trabalho hoje, mais especificamente sobre a competitividade exacerbada entre as empresas, influenciando no ambiente interno da organização, provocando distúrbios no comportamento e na saúde mental dos trabalhadores. Distúrbios estes que podem variar de uma simples desmotivação até os transtornos depressivos, que afetam as várias esferas de sua existência. Ao priorizar a tecnologia e as relações voltadas unicamente para o alcance de metas e desempenhos sempre inalcançáveis, as empresas deixam de lado o trabalhador, enquanto pessoa humana. Faz-se necessário repensar esses aspectos à luz da relação dialógica e da alternância das relações Eu-Tu e Eu-Isso, defendidas por Martin Buber, como forma de promover uma convivência mais harmoniosa e equilibrada nesse contexto.
\end{abstract}

Palavras-chave: Competitividade; Ambiente Organizacional; Relação Dialógica.

Abstract: The purpose of this article is to reflect on aspects that guide the work world today, more specifically on the high competitiveness between enterprises, affecting the internal environment of the organization, causing disturbances in behavior and mental health workers. These disorders that can range from a simple lack of motivation to depressive disorders, which affect the various spheres of their existence. By prioritizing technology and relationships geared solely to the achievement of performance goals, always unattainable, the companies put aside the worker, while human being. It is necessary to rethink these issues in light of the dialogical relationship and the alternation of the relationship I-Thou and I-it, championed by Martin Buber, in order to promote a more harmonious coexistence and balanced in that context.

Keywords: Competitiveness; Organizational Environment; Dialogical Relationship.

Resumen: Mi propósito es reflexionar sobre los aspectos que guían el mundo laboral hoy en día, más específicamente en la alta competitividad entre las empresas, que afectan el ambiente interno de la organización, causando perturbaciones en el comportamiento y los trabajadores de la salud mental. Estos trastornos que pueden ir desde una simple falta de motivación para los trastornos depresivos, que afectan a los distintos ámbitos de su existencia. Al dar prioridad a la tecnología y las relaciones exclusivamente orientado a la consecución de los objetivos de rendimiento y siempre inalcanzable, las empresas dejar de lado el trabajador, mientras que la persona humana. Es necesario repensar estas cuestiones a la luz de la relación de diálogo y la alternancia de la relación yo-tú y yo-, liderado por Martin Buber, a fin de promover una convivencia más armónica y equilibrada en ese contexto.

Palabras-clave: Competitividad; Medio Ambiente Organizacional; Relación Dialógica.

São por todos conhecidas as mudanças sofridas pela organização do trabalho no decorrer do tempo, mais especificamente a partir do século XX, através dos avanços tecnológicos, que influenciaram significativamente no desenvolvimento e aperfeiçoamento dos processos de produção e serviços, dos meios de comunicação, das relações das organizações com seus clientes, governo, sociedade, colaboradores. Um século em que a tecnologia "explodiu", o que, inequivocamente, repercutiu em grandes transformações econômicas, sociais, políticas e culturais.

Essas transformações influenciaram de forma significativa na organização do trabalho, tal qual o vivemos hoje. O estreitamento da comunicação, por meio da incorporação tecnológica maciça, tornou o mundo globalizado, gerando uma nova ordem: a competição entre as empresas. Competição esta cada vez mais acirrada e crescente.
De uma competição local, passou-se a global, tornando os produtos e serviços cada vez mais fáceis e rápidos de serem copiados em todo o mundo.

Sem dúvida, os mais favorecidos com essa nova estrutura organizacional tem sido o próprio homem enquanto cliente, acarretando em diferenciação de produtos e serviços, maior qualidade, valores acessíveis.

Contudo, dentro do universo corporativo, a história é bem outra. A competitividade externa generalizada tem levado à competição dentro da empresa, reforçando o sentimento de hostilidade entre os colaboradores, na luta por se manterem e se destacarem em sua atividade profissional. Em termos organizacionais, a imposição de metas sempre altas e desenfreadas, pressão por resultados, quadro de pessoal enxuto mediante a redução dos níveis hierárquicos, tem causado impactos na rotina e comportamento dos profissionais, influenciando signi- 
ficativamente sua saúde mental. Desde o alto executivo até o operário do chão de fábrica, todos estão expostos e vulneráveis a essas condições.

Para Barreto, essa nova organização "alterou completamente a relação com o tempo e o espaço e tem se desenvolvido cada vez mais como um fluxo, prescindindo de vínculos sociais duradouros ou referências no passado" (Freitas, Heloani, \& Barreto, 2008, p. 7). As transformações são rápidas e rápidos são os vínculos com as empresas. Estas se desvencilham com facilidade de funcionários que não mais representam resultados ao seu negócio, evidenciando a todo o momento o fantasma do desemprego. O homem passa a ser visto como um objeto ou um número, cuja utilidade tem hora para acabar. Esse "esquema de curto prazo das instituições modernas" (Sennett, 2006, p. 24) enfraquece o vínculo de confiança mútua, empobrecendo e fragilizando a relação profissional - empresa.

Pesquisas indicam que os trabalhadores sentem as consequências dessa nova forma de gestão, que "tem tornado-os vulneráveis ao desemprego, à queda de salários, à precariedade das condições de trabalho, a uma competição extremamente acirrada, à deterioração do clima no ambiente de trabalho e todas essas condições portadoras de violência" (Freitas et al., 2008, p. 7). Dessa forma, o mercado de trabalho (em seu sentido mais literal) é pautado pela capacidade de trabalhar sob pressão, ao ajustamento a mudanças constantes, à aprendizagem contínua, a resultados e metas sempre elevadas, a ter uma visão do todo e ao mesmo tempo ser especialista, ou seja, à busca pela perfeição.

Essa nova realidade se afirma sob o véu da globalização e da própria competição e "toda uma linguagem é ideologicamente construída para justificar os efeitos perversos" (Freitas et al., 2008, p. 24) que relações dessa natureza implicam, legitimando o mal-estar interno, configurando uma violência mental sutil e perigosa para a saúde dos trabalhadores.

Diante dessa realidade incerta, a identidade com o trabalho se esvai, uma vez que, por mais esforço que se lance, não há o reconhecimento esperado, com imposição de metas sempre inalcançáveis, através de atitudes que vão desde simples cobranças até humilhações extremamente vexatórias.

Essa conduta no trabalho é definida por Barreto como "assédio moral" (2008) e Hirigoyen e Barreto detectaram que ele se constitui por "uso abusivo do poder, ameaças recorrentes e sistemáticas, discriminações e intolerância que põem em risco a segurança, a saúde e o emprego" (Freitas et al., 2008, p. 52). São condutas destruidoras, que visam à violência psicológica, ameaçando a saúde mental do indivíduo, cujas consequências deixam rastros em todas as esferas de sua existência.

Barreto (Freitas et al., 2008, p. 42) chama a atenção para as diversas consequências dessa conduta desenfreada, resumindo-as em três categorias:
1) no nível individual - sua identidade e auto-estima são altamente atingidas. Uma vez existindo uma cobrança que não tem fim, o profissional tende a se considerar incapaz, improdutivo. Observa-se ainda uma redução na capacidade de concentração da pessoa, desmotivação, descrença, apatia, depressão, pensamentos autodestrutivos, transtornos de naturezas diversas, doenças psicossomáticas e até tentativas de suicídio.

2) no nível organizacional, ocorre o afastamento de pessoal por doenças e acidentes de trabalho; elevação de absenteísmo e o turn-over (rotatividade); perda de equipamentos pela desconcentração; queda de produtividade; custos da imagem da empresa, tanto para os colaboradores como para os clientes e sociedade; bem como redução de atratividade de talentos.

3) no nível social, é quase óbvio mencionar as conseqüências do que ocorre, proveniente dos itens 1 e 2: aumento de despesas médicas e de benefícios previdenciários, aposentadorias precoces, desestruturação familiar e social, custos jurídicos nos casos de requerimento de indenizações e à sobrecarga dos nossos já combalidos sistemas de saúde e de justiça.

São no tocante ao aspecto individual que se deterão essas reflexões. A pressão que se vive no ambiente organizacional é um processo, podendo ser inicialmente justificado por mudanças econômicas, sociais e tecnológicas. Porém, ela desce para um patamar em que atinge em cheio o indivíduo, como pessoa e profissional. A pessoa, no círculo vicioso desse ambiente, constrói um processo de autodegradação, que começa por considerar suas idéias inadequadas, atribuindo a si próprio (ou, em alguns casos, a outros) a culpa pela situação em que se encontra. Com o crescimento e frequência da situação, iniciam-se uma série de pensamentos recorrentes, "que favorecem o surgimento de agravos e danos à saúde mental, sendo responsáveis por mudanças do estado de ânimo, das emoções e alterações do comportamento, que podem evoluir para um estado depressivo" (Freitas et al., 2008, p. 62).

Para o profissional, esse ambiente representa o esmagamento de sua escolha profissional, colocando em dúvida sua competência e atestando sua inutilidade. Paradoxalmente, o trabalho, que é tido como referência para construção de sua identidade, que lhe dá o sentido de pertencimento, perde o seu valor, visto que já não o reconhece mais.

É no âmago dessa discussão que uma abordagem dialógica instaura um convite a refletir e repensar as modalidades de relações organizacionais.

Para Hycner, o dialógico é entendido como “(...) o contexto relacional total em que a singularidade de cada pessoa é valorizada; relações diretas, mútuas e abertas 
entre as pessoas são enfatizadas, e a plenitude e presença do espírito humano são honradas e abraçadas" (1997, p. 29-30).

Uma postura dialógica implica em compreender o outro em sua alteridade, abrindo caminhos para que seu potencial criador plante as suas sementes. Implica na aceitação do outro como um ser inteiro e não condenado por partes fragmentadas. Essa idéia vem de encontro às relações no ambiente organizacional, quando equipes multidisciplinares se alinham para um resultado final, em que cada um contribui com sua cota. Cota esta que vem alimentada pelo conhecimento técnico, pelas experiências de vida, as quais se somam aos conhecimentos e experiências dos demais para formar um todo.

Uma postura dialógica implica na "alternância rítmica das relações Eu-Tu e Eu-Isso" (Hycner \& Jacobs, 1997, p. 30). A relação Eu-Isso requer uma atitude objetiva diante dos fatos, é a leitura analítica dos dados, é o contexto objetivo e racional das relações. "É uma 'coisificação' do outro" (Hycner \& Jacobs, 1997, p. 33). Ao privilegiar o atingimento de um objetivo, o lado pessoa se torna fundo nesse momento.

A relação Eu-Tu implica em um momento de congraçamento, é encontrar o outro em sua totalidade, deixando vir à tona seu potencial criador, ao mesmo tempo em que o outro se permite viver por inteiro a relação. É acreditar no outro em sua singularidade, envolvida em um contexto relacional.

Transpondo esses conceitos para o ambiente organizacional, é possível verificar como a relação Eu-Isso acontece e é necessária. As organizações vivem da produção e/ou dos serviços prestados a uma determinada comunidade (local ou global), o que implica em atuar constantemente com números, desempenhos, metas a serem atingidas. Implica em analisar racionalmente fatos e dados, alinhando-os com as estratégias da empresa e as demandas de mercado. O modo Eu-Isso na empresa se caracteriza também pela tecnologia, o espaço físico, prazos e cronogramas, a serviço da sustentabilidade da empresa. É um componente forte na organização, em que o lado pessoa se materializa e se "coisifica” para que esses objetivos sejam alcançados. Desconsiderar esse componente é promover a anarquia, é navegar sem direção.

Concomitantemente, temos a relação Eu-Tu permeando os dados quantitativos e os indicadores de desempenho, abrindo espaço para a criatividade e a inovação. É o lado relacional, pessoal e humano da organização. "É uma experiência de apreciar a 'alteridade', a singularidade, a totalidade do outro, enquanto isso também acontece simultaneamente com a outra pessoa" (Hycner \& Jacobs, 1997, p. 33). É considerar o indivíduo como um todo: cabeça e coração, razão e emoção. A relação Eu-Tu permite que a pessoa exponha o seu todo, vivenciando a experiência de acertar e errar e de se responsabilizar por suas escolhas. A relação Eu-Tu é a alma da organi- zação, é o lado gente fazendo a diferença, é o potencial criador do inter-humano construindo o progresso das civilizações.

A abordagem dialógica abarca o todo do homem, o que significa conviver alternadamente as duas relações - Eu-Tu e Eu-Isso. "O modo Eu-Isso é vitalmente necessário para a sobrevivência e o Eu-Tu para a realização da condição de pessoa" (Hycner \& Jacobs, 1997, p. 68). Da mesma forma como ocorre na relação terapêutica, a relação organizacional que visa a saúde mental do trabalhador reveste-se de valores existenciais, incluindo uma relação pautada na concretude dos negócios, mas também no respeito à pessoa humana, provocando "uma ênfase no compromisso pleno e genuíno" (Hycner \& Jacobs, 1997, p. 67) entre profissional e empresa.

Contudo, ambientes degradantes ficam estagnados apenas na relação Eu-Isso, não permitindo aflorar o lado humano. Como o próprio Buber afirmou, "o ser humano não pode viver sem o Isso. Mas quem quer que viva somente com ele não é humano" (Hycner \& Jacobs, 1997, p. 68).

Para aflorar a relação Eu-Tu nas empresas, é necessário aceitar as diferenças como um aspecto inerente ao comportamento humano e que, por meio dele é que se chega a resultados maiores. "Suspendendo os pressupostos" (Hycner \& Jacobs, 1997, p. 39) que interferem nessa via, é preciso ver o outro como um ser único, singular, com aspectos potenciais que podem contribuir com a empresa, bem como seus aspectos "não potenciais" para aquela situação e momento, mas que fazem parte e completam seu todo. Ao mesmo tempo, é importante priorizar e introduzir esse ser singular no contexto relacional da organização, considerando que o homem vive em sua experiência esses dois aspectos: singularidade e relação.

Considerar o profissional e a empresa como um todo é papel de ambos, permanecendo na Presença desse contato, cuidadosos com o aqui e o agora da relação. $\mathrm{O}$ papel das lideranças é fundamental nesse processo de desenvolvedor de pessoas, estimulando e encorajando os colaboradores a uma atitude ativa em seu processo de crescimento profissional e de contribuinte do crescimento da empresa. Procurando seu aperfeiçoamento técnico, encorajando a consciência de seu desenvolvimento comportamental, criando condições para que as pessoas possam dar o melhor de si sem medo de errar, responsabilizando-se por suas escolhas, em consonância com os objetivos e estratégias da empresa, sem dúvida, remete a uma saudável alternância entre as necessidades concretas da empresa e as necessidades humanas do profissional e pessoa.

Concluindo, é importante refletir sobre as palavras de Sennett (2006, p. 176), sociólogo americano, estudioso sobre a manifestação do caráter nas relações de trabalho: "um regime (de trabalho) que não oferece aos seres humanos motivos para se ligarem uns aos outros não pode preservar sua legitimidade por muito tempo". 


\section{Referências}

Freitas, M. E., Heloani, R., \& Barreto, M. (2008). Assédio Moral no Trabalho. São Paulo: Cengace Learning.

Hycner, R., \& Jacobs, L. (1997). Relação e Cura em Gestaltterapia. São Paulo: Summus.

Sennett, R. (2006). A Corrosão do Caráter: Consequências pessoais do trabalho no novo capitalismo. Rio de Janeiro: Record.

Tranjan, R. A. (1997). A Empresa de Corpo, Mente e Alma: Um método inédito e eficaz para elevar a performance organizacional. São Paulo: Editora Gente.

Elina Eunice M. Pietrani - Psicóloga, Gestalt-terapeuta e Especialista em Gestão Empresarial (em curso). Atua desde 1999 na área da Psicologia Organizacional e, atualmente, trabalha como Consultora Organizacional na Alliage Consultoria em RH. E-mail: elinapietrani@ yahoo.com.br

Recebido em 02.03.2010 Aceito em 29.04.2010 